\title{
Farmland Irrigation Remote Monitoring System Based on Configuration Software and Multiple Serial Port Communication
}

\author{
Xiangbo $\mathrm{Han}^{1}$ and Zhanli $\mathrm{Liu}^{2, *}$ \\ ${ }^{1}$ College of Computer Science and Technology, \\ Shandong University of Technology, P.R. China \\ ${ }^{2}$ School of Agriculture and Food Engineering, \\ Shandong University of Technology, P.R. China \\ zhanliliu2009@yahoo.cn
}

\begin{abstract}
The design and implemental plan of the farmland irrigation remote monitoring system with variable frequency and constant pressure based Configuration Software and multiple serial port communication were introduced. The implementation of the communication between inverter, PLC, ADAM and KingView was studied. The data acquisition and monitoring scheme were analyzed. The hardware and software design of system were discussed in detail. It had been successfully applied to farmland irrigation, and the effects of automation and energy conservation had been as good as expected.
\end{abstract}

Keywords: Multi serial port communication, Configuration software, Farmland irrigation.

\section{Introduction}

With the rapid development of society and economy, farmland irrigation demands higher reliability and quality of water supply. Advancement of computer and automation technology makes the research of higher performance water supply system possible. Now most water supply systems have a lot of limitation, for example, little information acquisition, low manage and transfer. Information exchange among system and environment or equipments is difficult to achieve. It restricts greatly information acquisition and automation of corporation. Therefore, it plays an important realistic role in decreasing energy consumption and sharing information that researching the high performance and network monitoring system of constant-pressure water supply[1-2]. Based on configuration software, the monitoring system of constant-pressure water supply is developed by means of multiports, which satisfies requirement of corporation on water supply automation, and provides water supply corporation with a new resolution in order to realize unmanned watchkeeping, energy conservation and safety.

\footnotetext{
* Corresponding author.
} 


\section{System Constitution}

Water supply station has four wells, the first and third well is 120 meter deep, the second and fourth is 80 meter deep, the fifth is spare. There are four dive pumps of deep well, and one is spare among them. Three pumps can fit together freely, and spare pump can operate manually. The pressure of exit is $0.33 \mathrm{Mpa}$ constantly (0-1Mpa adjustably). Means of start-up is autoconnected serial portping voltage.

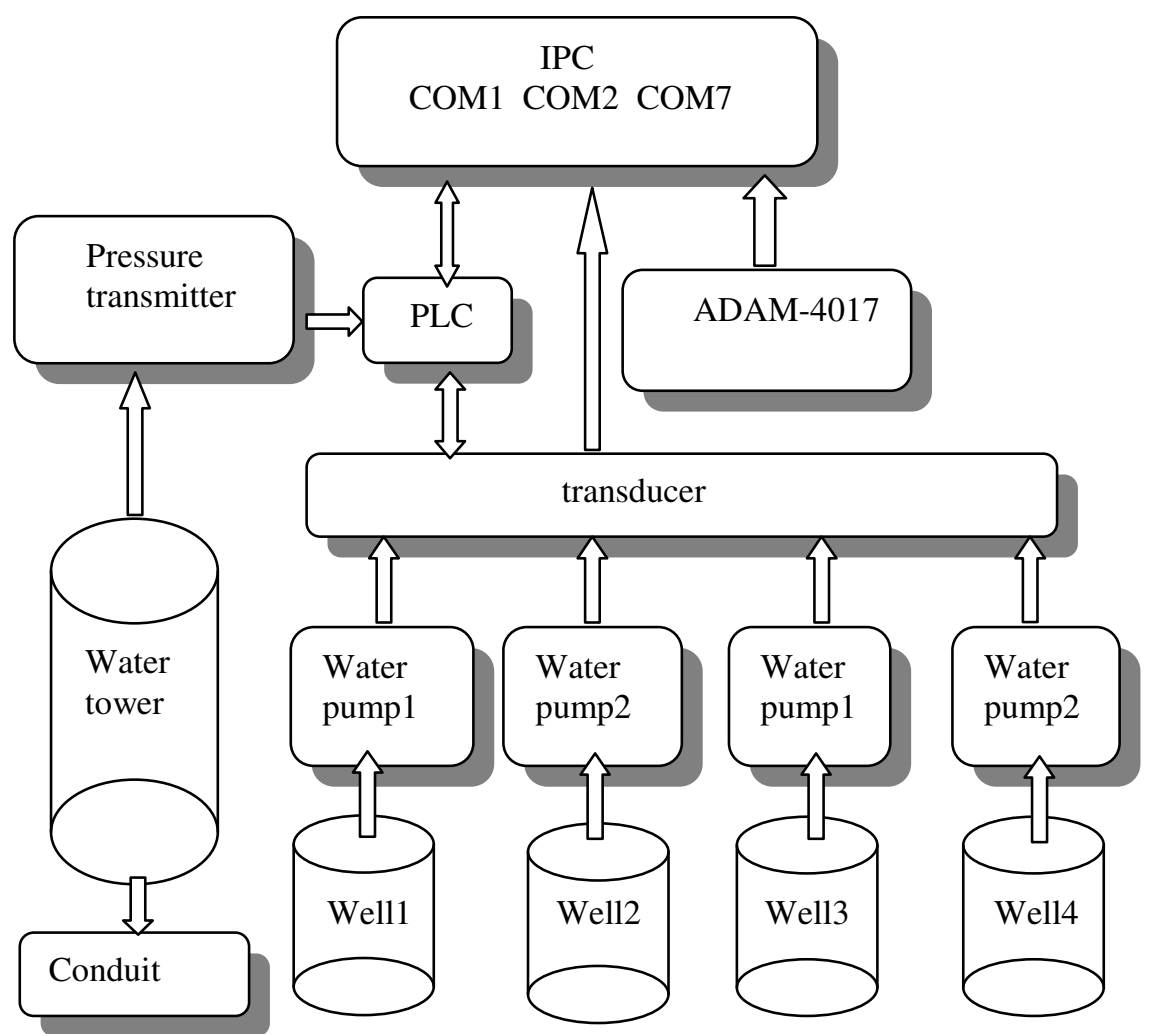

Fig. 1. The composition of farmland irrigation monitoring system

In this paper a new water supply surveillance system is developed, including IPC (industrial personal computer), PLC, transducer, intelligent module, and etc. Control subsystem is composed of advantech IPC 610 IPC, CPM2A programmable controller, SAMCIO - VM05 special water supply transducer. Signal acquisition subsystem is composed of ADAM - 4017, water level transmitter, Flow transmitter, current transmitter, voltage transmitter, and etc. Advantech intelligent module ADAM-4017 is used for analog signals, for example, voltage acquisition, current acquisition, and etc. ADAM-4017 is intelligent sensor interface module of built-in Microprocessor. It can be connected with serial port of IPC by RS232/RS485 interface module. It can be 
controlled by long-distance, communicating through 485 cable. Spot check data such as water level, flux, voltage, current and etc. are converted to standard signal (from 4 to $20 \mathrm{~mA}$ ) by sensor and transmitter, then transferred to central control cabinet in control house, then sent to digital panel meters through isolation module circuit. Operator can observe manually. Each digital panel meter is divided into one signal, which is sent to intelligent module ADAM-4017 in computer ground loop. Consequently computer can collect data.

Water supply volume and pressure of water supply system is instantaneous with water use need. Water pumps assume a lot if run according to rated flow and rated pressure, pressure fluctuates with flow. By pressure sensor of equipment exit the system transfers flow and pressure signal into standard electric signal, then send to PLC and ADAM-4017.By comparison, amplification, differential, integral, optimal control parameter is transferred into transducer, so that rotate speed of water pump can run according to practical water use and given pressure. We can achieve the aim to save energy efficiently, supply water with constant pressure and adjustable flow. In system bias removal, PID regulation can assure bias is zero so that system attains stability. Closed loop control system is composed of PLC, transducer, water pump and pressure sensor, and can carry out constant-pressure water supply (Fig.1).

\section{Communication Mode}

In monitoring system, IPC and PLC, transducer, analog collector module communicate through serial ports, as is shown in fig.1. Serial port extention adopts Advantech PCL849A card, affording four RS-232 serial ports. They can assure many equipments run at the same time, and afford interfaces for equipment replacement and upgrade. PCL849A card needs to set the site of extended serial port, discontinuity of use, communication speed, type of operating system and etc, be completed by jump wires on board card. While setting site of extended serial port and discontinuity, the paper avoids used sites and interrupt numbers in operating system. We can carry out communication with spot control equipments expediently by KingView device driver. KingView serial type logical device is its built-in serial port driver's logical name, corresponding with the actual devices connected to the computer serial port and supplying for KingView by the dynamic link library.

\section{Configuration Design}

In software, making use of configuration king KingView as engine configuration, interface of monitoring software is friendly, easily operational. Graph visualization is colorful, and circulation of spot equipments is shown dynamically in real time[3-5]. In automation monitoring, the software can show technique process graph, draw water level curve of water tower and running curve of water-lift engine at any moment and change cure of water pressure. It can reflect dynamically the curve change trend of checking parameters, collect spot data and states in real time and gather data. Report forms function of software can attain data print, management, sharing of longdistance data. 
In network, the monitoring software can run based on TCP/IP, so as to network communication from hypogynous computer to epistatic computer and long-distance server. As a customer server mode, server of the configuration system can set IO server, historical data server, alarming server, registering server, WEB server and etc according to system requirement. While a site of system is specified as a server, it can be other kind of server, and customer computer of other site server. The flexible network structure increases whole capacity of system and system function. WEB server using HTML and other technology equipment run the screen, a variety of dynamic curve and the report to generate dynamic web pages and realize remote network monitoring[6].

\section{References}

[1] Wu, S., Chen, Y., Cao, Z.C.: Development of on-board data collect ion system based on Fame View and PLC. Industrial Control Computer 19(2), 70-71 (2006)

[2] An, H.W., An, J., Bao, H.L.: The application of ABB PLC in the process monitoring and control for limekiln production. Techniques of Automation and Applications 27(1), 129-132 (2008)

[3] Zhou, Y.L.: Design of a configurable software based on $\mathrm{VC}^{++}$programming language in the integration of intelligent building system. Electronic Test (1), 46-50 (2008)

[4] Sun, Y.M., Shi, Y.Q.: Design of coal mine monitoring and controlling configuration software based on ActiveX. Mining Research and Development 27(2), 45-46 (2007)

[5] Liang, G., Bai, Y., Li, W.: Design and development of graph system in SFC configuration software. Control and Instruments in Chemical Industry 32(1), 29-33 (2005)

[6] Pang, X.Q., Chen, L.C., Chen, W.J.: Weather information issuance system based on web service. Computer Applications and Software 24(9), 88-90 (2007) 